\title{
Molecular Sieving Properties of Nanoporous Mixed-Linker ZIF-62: Associated Structural Changes upon Gas Adsorption Application
}

\author{
Jesus Gandara-Loe, Rocio Bueno-Perez, Alexander Missyul, David Fairen-Jimenez, \\ and Joaquin Silvestre-Albero*
}

Cite This: ACS Appl. Nano Mater. 2021, 4, 3519-3528

Read Online

\section{ACCESS | Lلll Metrics \& More | 回 Article Recommendations | si Supporting Information}

ABSTRACT: The evaluation of the flexibility in zeolitic imidazolate frameworks (ZIFs) has been very useful to understand their performance in gas adsorption and separation applications. Here, we have evaluated the adsorption properties of a nanoporous mixed-linker ZIF-62 using a combination of gas adsorption measurements, grand canonical Monte Carlo simulations, and synchrotron X-ray powder diffraction under operando conditions. While adsorption studies in nanoporous ZIF-62 at $77 \mathrm{~K}$ and atmospheric pressure predict a large $\mathrm{O}_{2} / \mathrm{N}_{2}$ separation ability, computational studies anticipate that the observed differences must be attributed to kinetic restrictions of $\mathrm{N}_{2}$ to access the internal porosity at cryogenic temperatures. Interestingly, upon a small increase in the adsorption temperature $(90 \mathrm{~K}$ vs 77 $\mathrm{K})$, both $\mathrm{N}_{2}$ and $\mathrm{O}_{2}$ are able to access the inner porous structure through the promotion of a phase transition (ca. 3.8\% volume expansion) upon gas

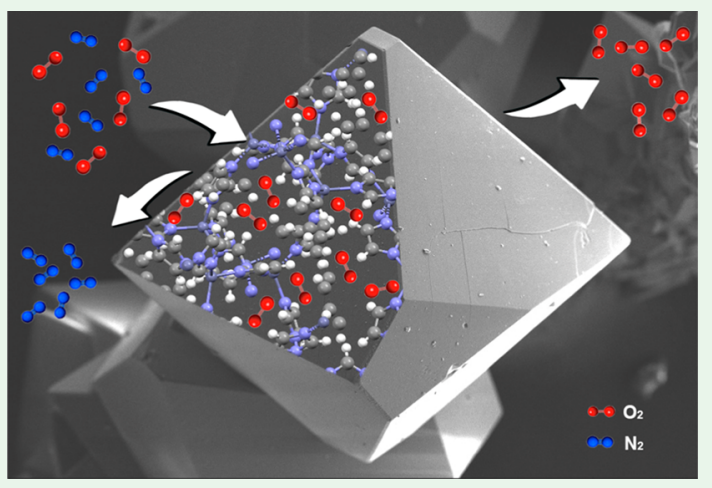
adsorption. This narrow phase (np) to expanded phase (ep) structural transition in ZIF-62 is completely suppressed above $150 \mathrm{~K}$. Based on the excellent molecular sieve properties of nanoporous ZIF-62 for $\mathrm{O}_{2} / \mathrm{N}_{2}$ at cryogenic temperatures, we extended our study to the adsorption of linear and branched hydrocarbons. This study predicts the preferential adsorption of alkanes over alkenes in ZIF-62 for small hydrocarbons $\left(\mathrm{C}_{2}\right)$, while in the case of $\mathrm{C}_{3}$ hydrocarbons and above, the adsorption process is mainly defined by kinetic restrictions.

KEYWORDS: ZIF-62, mixed linkers MOFs, structural changes, gas adsorption, molecular sieves

\section{INTRODUCTION}

Selective adsorption and separation of gases in industrial streams is highly challenging due to the similarity of the physicochemical properties such as size, shape, and polarity of the target molecules. ${ }^{1}$ Among others, excellent examples of complex separation processes include the discrimination between linear and branched hydrocarbons to increase the octane number, ${ }^{2}$ the $\mathrm{O}_{2} / \mathrm{N}_{2}$ separation from air, ${ }^{3}$ and the adsorption of $\mathrm{CO}_{2}$ and $\mathrm{N}_{2}$ for natural gas upgrading. ${ }^{4,5}$ These separation processes require the design of perfectly tailored porous networks with the required characteristics to promote the preferential adsorption of one of the components. Potential solutions include the design of specific pore size and shape to allow the selective adsorption of one of the molecules or the design of specific surface chemistry to promote specific adsorbate-framework interactions with the target molecules. Nanoporous zeolites and carbon molecular sieves have been widely applied due to their intrinsic characteristics such as a high surface area, large pore volume, and, in the specific case of the zeolites, a large polarity. ${ }^{6,7}$ Despite their performance, these materials are highly limited in terms of composition and associated versatility.
Among novel materials with highly promising performance for gas adsorption/separation, zeolitic imidazolate frameworks (ZIFs) can be considered one of the best candidates. ZIFs are a subclass of the metal-organic framework (MOF) family of materials, characterized by relatively high thermal and chemical stabilities due to the presence of a three-dimensional (3D) network that resembles zeolites, i.e., tetrahedral topology built up by metal ions (e.g., $\mathrm{Zn}$ and Co) linked to four imidazolate molecules with a similar configuration to the $\mathrm{Si}-\mathrm{O}-\mathrm{Si}$ angle found in zeolites. ${ }^{8}$ Besides stability, ZIFs exhibit unique potential for gas separation due to the combination of nanoporous-sized large cavities connected by small windows. Also, we and others have shown that some ZIFs present structural flexibility and that their $3 \mathrm{D}$ networks experience structural changes such as the swing effects or gate-opening phenomena, ${ }^{9-13}$ breathing ability, ${ }^{14}$ amorphization, ${ }^{15}$ and

Received: January 2, 2021

Accepted: March 2, 2021

Published: March 19, 2021 
phase-transition processes. ${ }^{16,17}$ These structural changes are associated with external stimuli such as high temperature, ${ }^{18}$ high pressure, ${ }^{9,15,19}$ or the exposure and adsorption of certain gases. ${ }^{20}$ These unique structural responses open the gate toward the application of ZIFs in gas separation processes based not only on steric effects (size and shape of the pore cavities) but also on the exploitation of specific adsorbentadsorbate interactions able to induce structural changes in the ZIF, i.e., able to compete with the bonding and nonbonding interactions within the structure.

Flexibility and separation principles have been widely explored in the literature and mostly in the case of nanoporous sodalite ZIF-8 and ZIF-7 to promote selective adsorption of hydrocarbons, ${ }^{12,21}$ as well as $\mathrm{H}_{2}, \mathrm{CO}_{2}, \mathrm{O}_{2}, \mathrm{~N}_{2}$, and $\mathrm{CH}_{4}{ }^{22,23}$ These results anticipate that, despite having a similar structure and sometimes even the same topology, the nature of the imidazolate ligand defines their adsorption performance. An excellent example that can be found in the literature is the completely different nitrogen adsorption behavior of the prototypical ZIF-8 and ZIF-7 materials, , 11,17,20,24,25 with sod topology, and ZIF-4, with cag topology. ${ }^{14}$ As described above, this different behavior has been attributed to the different interactions between the target molecules and the ZIF framework, including the nature of the intranet interactions, defined by the imidazolate linker and the metal.

The versatility of ZIFs has been tremendously expanded upon the discovery of mixed-linker networks, i.e., the preparation of new porous networks through the combination of different imidazolate-based linkers. This is, for example, the case of ZIF-62 [Zn(imidazolate $\left.)_{2-x}(\text { benzimidazolate })_{x}\right]$, which is isostructural of ZIF-4, sharing the same imidazolate linker but with a small proportion $(x \sim 0.25)$ of the bulkier benzimidazolate $\left(\mathrm{bim}^{-}\right)$linker. ${ }^{26}$ Despite sharing the same topology (cag) and having similar unit cell parameters to that of ZIF-4, recent studies have shown that the physicochemical properties of these two ZIFs are rather different. In particular, ZIF-62 exhibits a lower melting point and a wider melting range than ZIF-4 due to the higher electron-donating properties and larger steric hindrance of bim $^{-27,28}$ Interestingly, ZIF-62 is able to form glass membranes ( $a_{\mathrm{g}}$ ZIF-62) upon a melt-quenching treatment with excellent selectivity values for $\mathrm{H}_{2} / \mathrm{CH}_{4}, \mathrm{CO}_{2} / \mathrm{N}_{2}$, and $\mathrm{CO}_{2} / \mathrm{CH}_{4}$ mixtures, although associated with a low adsorption capacity. ${ }^{29}$ Despite the high interest in its glass phases, the number of studies dealing with the adsorption and structural properties of the crystalline ZIF62 phase is rather limited.

Taking into account the unique adsorption performance of ZIFs and their intrinsic structural properties, the main goal of this manuscript is to understand the molecular sieve and adsorption performance of ZIF-62 and the associated structural changes upon gas adsorption. In spite of ZIF-62 being analogous to ZIF-4, here we show that the gas adsorption behavior and separation performance of ZIF-62 follow a completely different scenario associated with its distinct structural phenomena.

\section{EXPERIMENTAL SECTION}

2.1. Synthesis of ZIF-62. ZIF-62 was synthesized using a solvothermal method similar to those reported in the literature. ${ }^{30}$ Imidazole $(0.525 \mathrm{~g}, 7.72 \mathrm{mmol})$ and benzimidazolate $(0.130 \mathrm{~g}, 1.10$ mmol) were mixed with $\mathrm{Zn}\left(\mathrm{NO}_{3}\right)_{2} \cdot 4 \mathrm{H}_{2} \mathrm{O}(0.8 \mathrm{~g}, 3.06 \mathrm{mmol})$ in a solid mixture. The mixture was dissolved in $60 \mathrm{~mL}$ of $\mathrm{N}, \mathrm{N}$ dimethylformamide (DMF) and kept under agitation for $30 \mathrm{~min}$.
Afterward, the liquid solution was transferred in a Teflon vessel (100 $\mathrm{mL}$ ) and heated in an autoclave to $403 \mathrm{~K}$ with a heating rate of $5 \mathrm{~K} /$ $\mathrm{min}$ and held at this temperature for $48 \mathrm{~h}$. Once at room temperature, the sample was washed several times with $30 \mathrm{~mL}$ of DMF $(\times 2)$ and then with $30 \mathrm{~mL}$ of methanol $(\times 2)$. Finally, the sample was exposed to a solvent exchange process with methanol $(30 \mathrm{~mL} /$ day $)$ for 2 days. To remove the excess methanol, ZIF-62 was filtered and dried in air at $343 \mathrm{~K}$ for $2 \mathrm{~h}$. The resulting white solid was activated under dynamic vacuum at $493 \mathrm{~K}$ for $8 \mathrm{~h}$. Based on the synthesis molar ratio, the theoretical MOF composition is ZIF-62 [ $\mathrm{Zn}$ (Imidazole $)_{1.64}$ (benzimidazole $)_{0.36}$.

2.2. Synchrotron X-ray Powder Diffraction Analysis (SXRPD). Synchrotron X-ray powder diffraction data (SXRPD) were collected on the powder diffraction end station of the MSPD beamline at ALBA synchrotron (Spain). Experiments were performed in the capillary reaction cell (fused silica capillary; inner diameter, 0.7 $\mathrm{mm}$; outer diameter, $0.85 \mathrm{~mm}$ ), using a MYTHEN detector and a wavelength of $0.4124 \AA$. SXRPD measurements were performed in the activated ZIF- 62 material at $90 \mathrm{~K}$ before and after dosing oxygen and nitrogen at ranging pressures $(0.3,0.6$, and 1 bar). The samples were equilibrated for $30 \mathrm{~min}$ at $1 \mathrm{bar}$, the measurement was repeated to ensure the stability of the structure, and then the sample temperature was scanned from 90 up to $300 \mathrm{~K}$ under constant pressure.

2.3. Physicochemical Characterization. Thermogravimetric analysis (TGA) was carried out in air using a ceramic crucible and a heating ramp of $10 \mathrm{~K} / \mathrm{min}$ up to $1273 \mathrm{~K}$. All experiments were performed with a TG-DTA METTLER TOLEDO equipment model TG/SDTA851e/SF/1100.

Field emission scanning electron microscopy (FESEM) studies were performed using a Merlin VP Compact equipment from Zeiss, equipped with an energy-dispersive spectroscopy (EDS) microanalysis system Quantax 400 from Bruker. This equipment has resolutions of $0.8 \mathrm{~nm}$ at $15 \mathrm{kV}$ and $1.6 \mathrm{~nm}$ at $1 \mathrm{kV}$. ZIF- 62 was kept in methanol until measurement.

$\mathrm{N}_{2}$ and $\mathrm{O}_{2}$ isotherms at 77,195 , and $298 \mathrm{~K}$ were performed in a homemade fully automated manometric equipment designed and constructed by the LMA group. The samples were previously degassed for $8 \mathrm{~h}$ at $493 \mathrm{~K}$ under vacuum $\left(10^{-3} \mathrm{~Pa}\right)$. Gas hydrocarbon adsorption isotherms at $298 \mathrm{~K}$ were carried out under strict equilibrium conditions (equilibrium points, 10; interval time, $30 \mathrm{~s}$; sorption rate limit, $0.01 \mathrm{Torr} / \mathrm{min}$ ). These measurements were performed in a homemade fully automated manometric device designed by the LMA group and now commercialized by Quantachrome by Anton Paar as Vstar.

2.4. Computational Details. Monte Carlo simulations were performed using RASPA software. ${ }^{31}$ First, grand canonical Monte Carlo (GCMC) simulations were carried out to compute adsorption isotherms of $\mathrm{O}_{2}$ and $\mathrm{N}_{2}$ in ZIF-62 at 77, 195, and $298 \mathrm{~K}$, and to estimate the saturation loading at 0.2 bar and $77,97,117,137,157$, $177,195,215,235,255,275$, and $298 \mathrm{~K}$. Simulations were arranged in cycles of trial moves, including translations, rotations, insertions, and deletions of molecules. Results for uptake and energy in the system were obtained after 30000 initialization cycles and 100000 production cycles. To compare the energies of the system at different temperatures regardless of the uptake, the values of total energy and host-guest and guest-guest interactions were obtained from the corresponding GCMC simulations, divided by the number of molecules adsorbed, and converted from $\mathrm{K}$ to $\mathrm{kJ} / \mathrm{mol}$. Pore size distribution for ZIF-62 was computed with RASPA and the textural properties with PoreBlazer. $^{32}$

Van der Waals interactions in the system were described by $12-6$ Lennard-Jones (LJ) potentials with a cutoff at $12.8 \AA$, and LorentzBerthelot mixing rules were used to calculate adsorbate-adsorbate and adsorbate-adsorbent interactions. Electrostatic interactions were described by Coulomb potentials and computed using Ewald summations. The simulation box was at least twice the cutoff, for which a $2 \times 2 \times 2$ supercell was chosen, and periodic boundary conditions were applied. TraPPE force field was used to model $\mathrm{O}_{2}{ }^{33}$ and $\mathrm{N}_{2}{ }^{34}$ molecules. ZIF- 62 was modeled as rigid with its framework 
atoms fixed at their crystallographic positions, which were taken from our own data (see CIF files in the Supporting Information). The LJ parameters and partial charges for the framework atoms of ZIF-62 were derived from previously published force fields for ZIF materials. ${ }^{35,36}$ All of these force field parameters are summarized in Tables S1 and S2, and the description of the models is shown in Figure S1. The input files, models and force field definitions required to repeat these simulations in RASPA and reproduce the computational results are provided as a zip file attached to the Supporting Information.

\section{RESULTS AND DISCUSSION}

3.1. Physicochemical Characterization of ZIF-62. The quality of the synthesized ZIF-62 crystals (Scheme 1) was

Scheme 1. Schematic Illustration of (A) the Crystal Structure of Zif62 ( $\mathrm{Zn}$ ), Including the Inorganic and Organic Building Units (the Positions of the $\mathrm{Bim}^{-}$Linkers Are Highlighted in Orange), and (B) the Solvent Accessible Volume (Blue Surface) of a Unit Cell of Zif-62 (Zn)

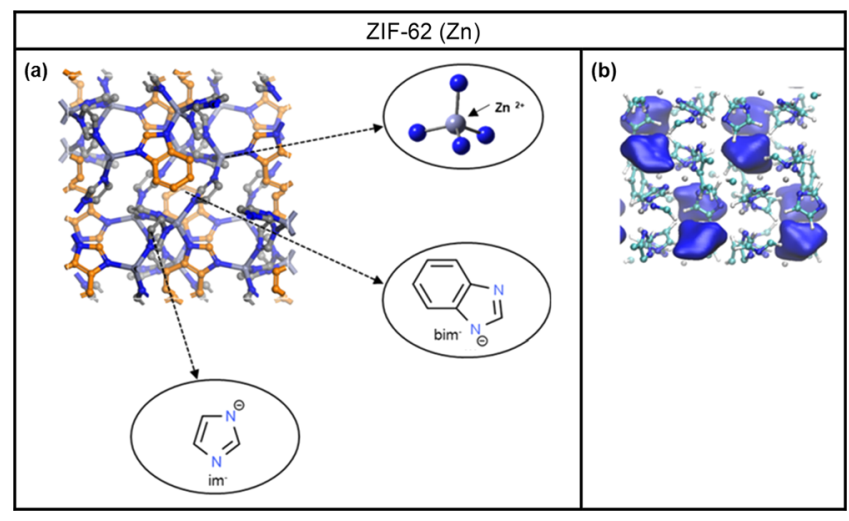

evaluated in a first step using synchrotron X-ray diffraction analysis (SXRPD). Figure S2 compares the experimental SXRPD pattern obtained with the simulated one; the excellent match confirms the good quality of the synthesized crystals.

The unit cell parameters of the desolvated material obtained from the Rietveld refinement, with an orthorhombic space group Pbca, are $a=15.4659$ (4) $\AA, b=15.5981(3) \AA$, and $c=$ $17.9667(4) \AA$, with a volume $v=4334.3(2) \AA^{3}$. ZIF-62 crystals are rather uniform in size (ca. 5-20 $\mu \mathrm{m})$ with well-defined crystallographic facets arranged in a truncated octahedral shape-i.e., truncated corners within the double pyramid (Figure 1). Figure S3 shows the thermogravimetric analysis of the as-synthesized material, exhibiting a first weight loss of ca. $10 \%$ between 400 and $650 \mathrm{~K}$ due to the removal of the solvent (mainly due to DMF remaining in the pores, although we cannot exclude some residual methanol) and a second weight

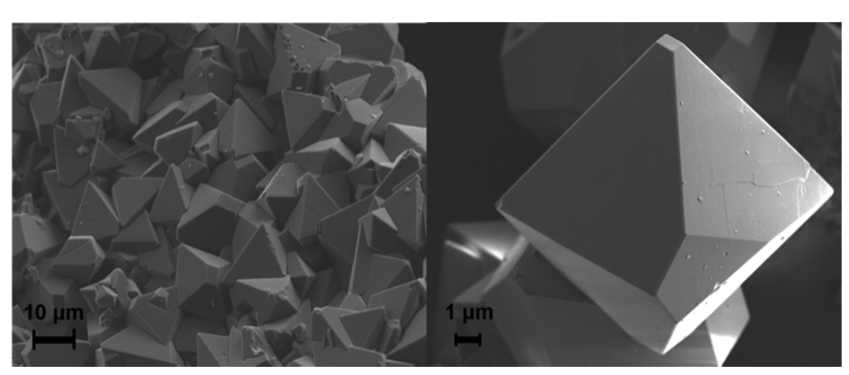

Figure 1. FSEM image of the ZIF-62 crystals. loss of ca. $55 \%$ between 700 and $1273 \mathrm{~K}$ due to the decomposition of the framework. It is important to highlight the high temperature required to remove the DMF compared to other ZIFs such as ZIF-7 and ZIF-4, where activation temperatures between 373 and $423 \mathrm{~K}$ are usually sufficient to activate the porosity. The requirement of high temperature for activation is confirmed when pretreating the ZIF-62 sample under ultrahigh-vacuum conditions at either 413 or $493 \mathrm{~K}$ for $12 \mathrm{~h}$ (Figure S4). In these samples, the complete removal of the solvent is effective only after a pretreatment at $493 \mathrm{~K}$.

3.2. Adsorption of $\mathrm{N}_{2}$ and $\mathrm{O}_{2}$ in ZIF-62. We have evaluated the adsorption behavior of ZIF-62 toward $\mathrm{N}_{2}$ and $\mathrm{O}_{2}$ at different temperatures. The separation of these two molecules is a challenging process due to their similar size and shape (kinetic diameter for $\mathrm{N}_{2}, 0.364 \mathrm{~nm}$, and for $\mathrm{O}_{2}$, $0.346 \mathrm{~nm}$ ). Traditionally, their separation using zeolites (e.g., zeolite $13 \mathrm{X}$ ) and MOFs is based on the faster adsorption kinetics for $\mathrm{O}_{2}$ over $\mathrm{N}_{2}$ on rapid pressure swing adsorption units. $^{37,38}$ Figure 2 shows the experimental adsorption isotherms for $\mathrm{N}_{2}$ and $\mathrm{O}_{2}$ at 77,195 , and $298 \mathrm{~K}$. At $77 \mathrm{~K}$, ZIF-62 exhibits a large adsorption capacity for $\mathrm{O}_{2}$ (up to 8 $\mathrm{mmol} / \mathrm{g}$ at saturation pressure). This value is among the best values reported and predicted in the literature for $\mathrm{O}_{2}$ adsorption in MOFs. ${ }^{39-41}$ For instance, Dincă et al. reported an adsorption capacity for $\mathrm{Cu}(\mathrm{BDT})$ of $14 \mathrm{mmol} / \mathrm{g}$ at $77 \mathrm{~K}$ and Humphrey et al. reported up to $6 \mathrm{mmol} / \mathrm{g}$ for CUK-1 at $87 \mathrm{~K}^{40,41}$ Interestingly, the performance of ZIF-62 is quite exceptional since the large uptake for $\mathrm{O}_{2}$ is accompanied by a high selectivity to adsorb $\mathrm{O}_{2}$ over $\mathrm{N}_{2}$ at cryogenic temperatures. This selectivity is preserved over the whole relative pressure range evaluated (separation factor, calculated from the $\mathrm{O}_{2} / \mathrm{N}_{2}$ ratio of amounts adsorbed at $p / p_{0}=0.4$, above 68). The high separation factor value is among the best reported in the literature so far for $\mathrm{O}_{2} / \mathrm{N}_{2}$ separation in MOFs at $77 \mathrm{~K} .^{41,42}$ Unfortunately, these excellent adsorption properties vanish under less energy-demanding experimental conditions, i.e., at higher temperatures. At $195 \mathrm{~K}$, both molecules exhibit a Type I adsorption isotherm with full accessibility to the inner porous structure, slightly favored for $\mathrm{O}_{2}$ at 1 bar $\left(1.8\left(\mathrm{O}_{2}\right)\right.$ vs 1.6 $\mathrm{mmol} / \mathrm{g}\left(\mathrm{N}_{2}\right)$; separation factor, $\mathrm{O}_{2} / \mathrm{N}_{2}$ ratio, of 1.14$)$. At 298 $\mathrm{K}$, the preferential adsorption of $\mathrm{O}_{2}$ vanishes, with a total uptake of $0.15 \mathrm{mmol} / \mathrm{g}$ and no selectivity. However, at this point, it is important to highlight that, although under equilibrium conditions both probe molecules exhibit similar accessibility to the inner porous structure at 195 and $298 \mathrm{~K}, \mathrm{O}_{2}$ diffusion is always favored over $\mathrm{N}_{2}$ (Figure S5). Indeed, the time needed for each point of the isotherm to reach equilibrium is around 2 times larger for $\mathrm{N}_{2}$ compared to $\mathrm{O}_{2}$, at least in the low-pressure regime.

The problems of accessibility for nitrogen in ZIFs at $77 \mathrm{~K}$ have been widely reported in the literature. For instance, computational studies, in situ synchrotron X-ray diffraction and inelastic neutron scattering (INS) studies have shown that, upon nitrogen adsorption, ZIF-8 structure experiences a gateopening effect through the swinging of the imidazolate linker. ${ }^{9,11}$ In the case of ZIF-7 and ZIF-4, although nitrogen adsorption is kinetically restricted and requires large equilibration times, synchrotron X-ray diffraction measurements have clearly shown a phase transition from a highly dense narrow pore phase to an expanded phase, i.e., these ZIFs are able to breathe. ${ }^{14,24}$ Contrarily to these ZIFs, nitrogen adsorption in ZIF-62 at $77 \mathrm{~K}$ is rather zero over the whole pressure range evaluated. Even when the $\mathrm{N}_{2}$ isotherms are 


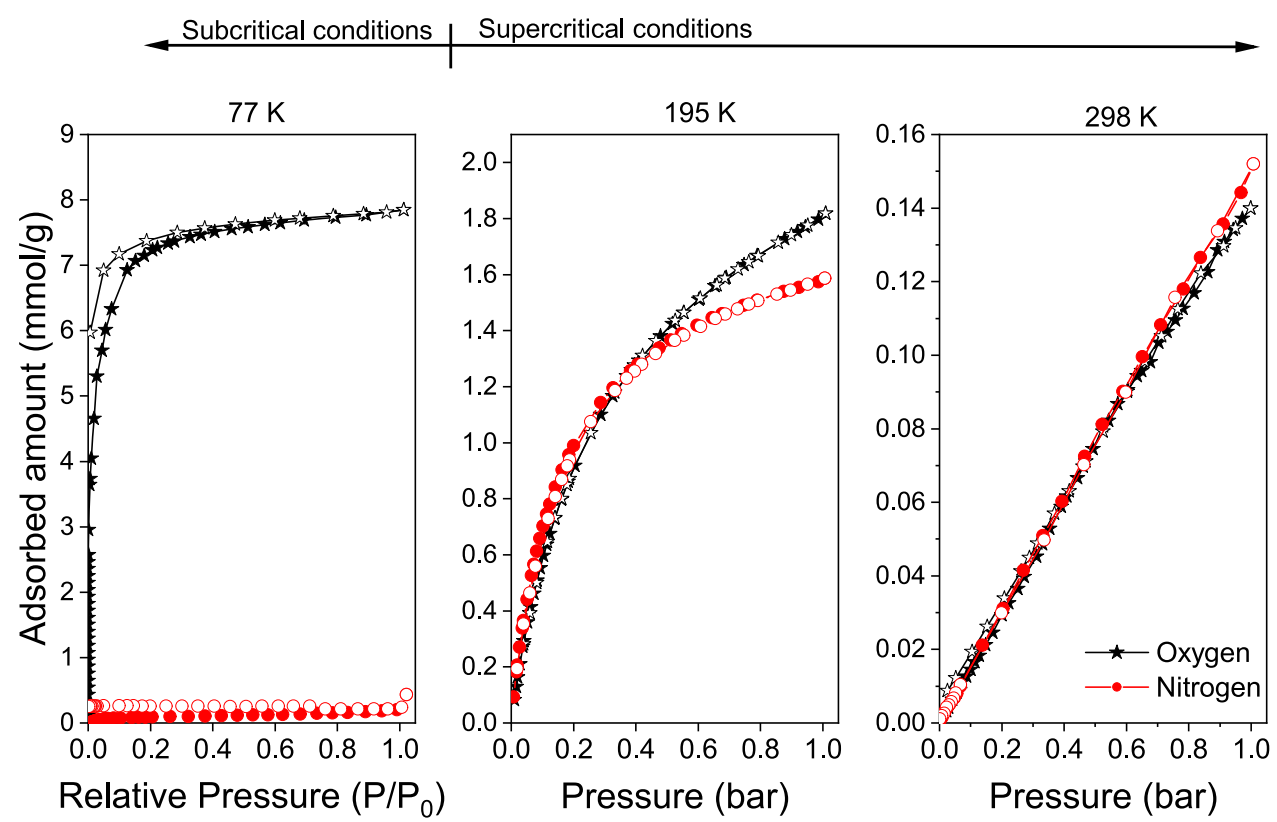

Figure 2. $\mathrm{N}_{2}$ and $\mathrm{O}_{2}$ adsorption/desorption isotherms in ZIF-62 at 77, 195, and $298 \mathrm{~K}$.

performed under more strict equilibrium conditions (Figure S6), although nitrogen uptake slightly improves, the obtained values are far from the adsorption capacity for a similar molecule such as $\mathrm{O}_{2}$. The size of the crystals is another parameter defining the flexibility in ZIFs. ${ }^{43}$ However, in the case of ZIF-62, a similar adsorption performance is observed after a milling process (Figure S7). In this specific case, $\mathrm{N}_{2}$ adsorption slightly increases, thus reflecting the kinetic limitations of $\mathrm{N}_{2}$ to access the inner porous structure in ZIF62 , although the final uptake remains far from the values achieved with $\mathrm{O}_{2}$.

In summary, these results show that contrary to ZIF-4 and ZIF-7, the combination of imidazole and benzimidazole linkers in ZIF-62 gives rise to novel adsorption properties, with a complete exclusion of the $\mathrm{N}_{2}$ molecule from the inner porous structure, while $\mathrm{O}_{2}$, with a similar kinetic diameter, exhibits a high uptake. Consequently, these effects must not be attributed to any individual linker but rather to the synergy between them.

3.3. Computational Data. Figure $S 8$ shows the available pore space of ZIF-62 and the pore size distribution obtained from the crystallographic data. Simulations show that ZIF-62 structure is characterized by cages of $0.46 \mathrm{~nm}$ in diameter interconnected by three narrow windows of $0.14 \mathrm{~nm}$, each of which connects them to adjacent cages. Since the window size is narrower than the size of $\mathrm{N}_{2}$ and $\mathrm{O}_{2}$, we would expect a structural distortion in ZIF-62, at least locally, leading to the swing of the organic linkers and the gate opening that will allow the diffusion of the adsorbates. To get a better insight into the differences between $\mathrm{N}_{2}$ and $\mathrm{O}_{2}$, we have modeled their adsorption using grand canonical Monte Carlo (GCMC) simulation. We note here that all of the simulations are done in a rigid model and, due to the nature of GCMC predictions, they do not distinguish between accessible and closed porosity (i.e., a molecule does adsorb if the site is favorable even if the windows to access the porosity are too narrow to allow the molecules to diffuse). Figures S9 and S10 compare the GCMC simulations and experimental isotherms at 77,195 , and $298 \mathrm{~K}$ for $\mathrm{O}_{2}$ and $\mathrm{N}_{2}$, respectively. In the case of $\mathrm{O}_{2}$, the simulated isotherms match the experimental isotherms at the three temperatures evaluated, thus validating the model used. However, the scenario changes significantly for $\mathrm{N}_{2}$. Although the simulation perfectly predicts the adsorption performance at 195 and $298 \mathrm{~K}$, it overestimates the adsorption performance at $77 \mathrm{~K}$. Indeed, the $\mathrm{N}_{2}$ predicted uptake at $77 \mathrm{~K}$ (ca. 5 and 6 $\mathrm{mmol} / \mathrm{g}$ at 0.2 and $0.8 \mathrm{bar}$, respectively) is far from the experimental value $(0.43 \mathrm{mmol} / \mathrm{g}$ at $0.8 \mathrm{bar})$. To make this idea clearer, Figure 3 shows the evolution of the GCMC

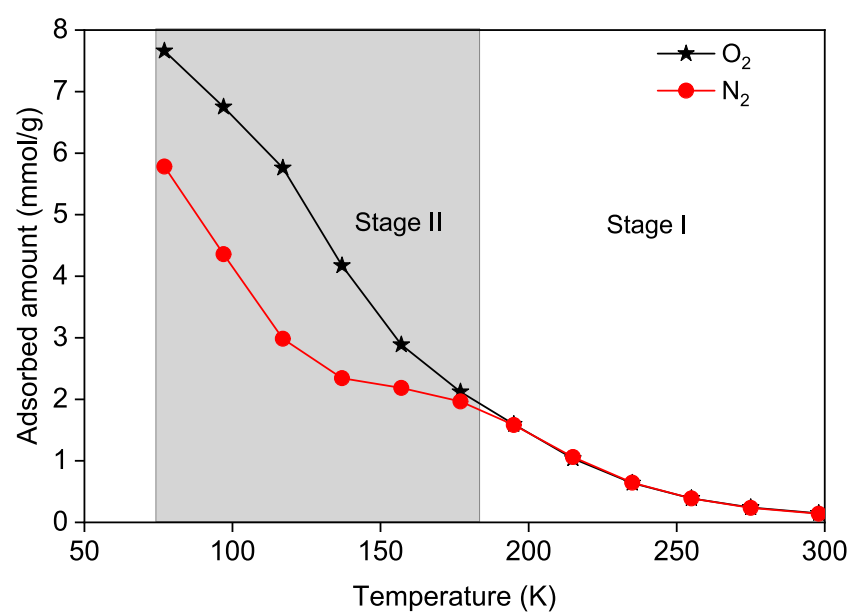

Figure 3. ZIF-62 loaded computationally with $\mathrm{O}_{2}$ (black stars) and $\mathrm{N}_{2}$ (red circles) at 0.2 bar as a function of the temperature. Stage I (white area) shows similar adsorbed amounts for $\mathrm{N}_{2}$ and $\mathrm{O}_{2}$ and spans from 170 to $298 \mathrm{~K}$. Stage II (gray area) shows different adsorption behavior for $\mathrm{N}_{2}$ and $\mathrm{O}_{2}$ and spans from 77 to $170 \mathrm{~K}$.

adsorbed amount for $\mathrm{N}_{2}$ and $\mathrm{O}_{2}$ when changing the temperature. Based on the simulation, one can appreciate two well-defined stages. In Stage I, above $170 \mathrm{~K}$, the adsorbed amounts of $\mathrm{N}_{2}$ and $\mathrm{O}_{2}$ are similar, showing a progressive decay with increasing temperature. In Stage II, below $170 \mathrm{~K}$, both $\mathrm{N}_{2}$ and $\mathrm{O}_{2}$ show an exponential increase in the amount adsorbed-with the increase being more important for $\mathrm{O}_{2}$ 
and reaching total uptakes of $7.5 \mathrm{mmol} / \mathrm{g}\left(\mathrm{O}_{2}\right)$ and $5.1 \mathrm{mmol} /$ $\mathrm{g}\left(\mathrm{N}_{2}\right)$ at $77 \mathrm{~K}$; this results in a separation factor of 1.5 .

Table S3 shows the host-guest and guest-guest contributions to the energy calculated at saturation pressure. According to Figures S9 and S10, the maximum uptake is reached at 1 bar except for oxygen at $77 \mathrm{~K}$, where the saturation pressure is 0.2 bar. In Stage I, where the adsorption performances are comparable and well predicted by the simulation (i.e., 298$195 \mathrm{~K})$, there is no significant difference in the host-guest and guest-guest interactions. In Stage II, while the host-guest interactions are similar-slightly larger for $\mathrm{O}_{2}$ than for $\mathrm{N}_{2}$ $\left(-14.436 \mathrm{~kJ} / \mathrm{mol}, \mathrm{O}_{2}\right.$; and $\left.-14.041 \mathrm{~kJ} / \mathrm{mol}, \mathrm{N}_{2}\right)$-the guestguest interaction is 3.3 times higher for $\mathrm{O}_{2}(-1.25 \mathrm{~kJ} / \mathrm{mol})$ than for $\mathrm{N}_{2}(-0.38 \mathrm{~kJ} / \mathrm{mol})$. Although the net contribution of the guest-guest interaction is small compared to the hostguest, the higher interaction between $\mathrm{O}_{2}$ molecules together with a slightly higher interaction between ZIF-62 and $\mathrm{O}_{2}$ is probably the reason for the higher amount adsorbed compared to that of $\mathrm{N}_{2}$.

We further explored the evolution of the energy in the system and the behavior of the two gases adsorbed in ZIF-62. Figure S11 shows the total energy and the host-guest and guest-guest contributions corresponding to the adsorption values shown in Figure 3. It is worth noting that the values of energy are calculated based on the energetic contribution per molecule. Between 150 and $298 \mathrm{~K}$ (Stage I), the total energy is mostly coming from the host-guest contributions, being the guest-guest contributions negligible, with the total energy being around $0.84 \mathrm{~kJ} / \mathrm{mol}$ higher for $\mathrm{N}_{2}$ than for $\mathrm{O}_{2}$. This trend is inverted when the temperature decreases below $150 \mathrm{~K}$ (Stage II), and, at $77 \mathrm{~K}$, the total energy of $\mathrm{O}_{2}$ increases to be $0.89 \mathrm{~kJ} / \mathrm{mol}$ higher than that of $\mathrm{N}_{2}$. At $77 \mathrm{~K}$, the host-guest contributions of $\mathrm{N}_{2}$ and $\mathrm{O}_{2}$ are virtually the same $(-14.45 \mathrm{~kJ} /$ $\mathrm{mol})$, and the guest-guest contributions are -1.24 and -0.35 $\mathrm{kJ} / \mathrm{mol}$ for $\mathrm{O}_{2}$ and $\mathrm{N}_{2}$, respectively. In the case of $\mathrm{O}_{2}$, this interaction accounts for an $8 \%$ of the total energy and is responsible for compensating the lower host-guest interactions of $\mathrm{O}_{2}$ below $137 \mathrm{~K}$. Even if Monte Carlo simulations do not consider kinetic effects during the adsorption process, they were able to capture key differences during the adsorption of $\mathrm{O}_{2}$ and $\mathrm{N}_{2}$ in ZIF-62. The cumulative difference in the total energy for both gases suggests that the collective effect of the stronger interactions of $\mathrm{O}_{2}$ might be the reason for which it could open the gate of the porosity at $77 \mathrm{~K}$, whereas the weaker interactions of $\mathrm{N}_{2}$ underlie the kinetic problems of $\mathrm{N}_{2}$ to get access the pores of ZIF-62 due to the inability of $\mathrm{N}_{2}$ to promote structural changes in ZIF-62.

3.4. Synchrotron X-ray Diffraction Measurements Upon Adsorption. To evaluate the potential structural changes in ZIF-62 upon adsorption and to understand the performance of $\mathrm{N}_{2}$ and $\mathrm{O}_{2}$ at the evaluated temperatures, we performed synchrotron X-ray powder diffraction (SXRPD) measurements under operando conditions. To this end, we first cooled ZIF-62 down to $90 \mathrm{~K}$ and then dosed it with $\mathrm{O}_{2}$ or $\mathrm{N}_{2}$ from low pressures up to 1 bar.

At $90 \mathrm{~K}$ and vacuum conditions, the activated ZIF-62 exhibits an orthorhombic structure with $a=15.3978$ (6) $\AA$, $b=$ 15.4138(6) $\AA, c=17.9555(6) \AA$, and $v=4261.5(4) \AA^{3}$. These values correspond to a unit cell contraction upon cooling of ca. $1.7 \%$, in close agreement with previous data with ZIF-4. ${ }^{14}$ Once at $90 \mathrm{~K}$, the reaction cell was pressurized with $\mathrm{O}_{2}$ up to 1 bar. Figure S12 shows the SXRPD patterns of ZIF-62 at $90 \mathrm{~K}$ loaded with $\mathrm{O}_{2}$ at different pressures. Upon oxygen incorporation, there is a decrease in the intensity of the main diffraction peaks at $3.0,3.4,3.7,4.0$, and $4.5^{\circ}$; besides, new peaks appear as shoulders at $2.9,3.9$, and $4.4^{\circ}$. Figure 4 shows

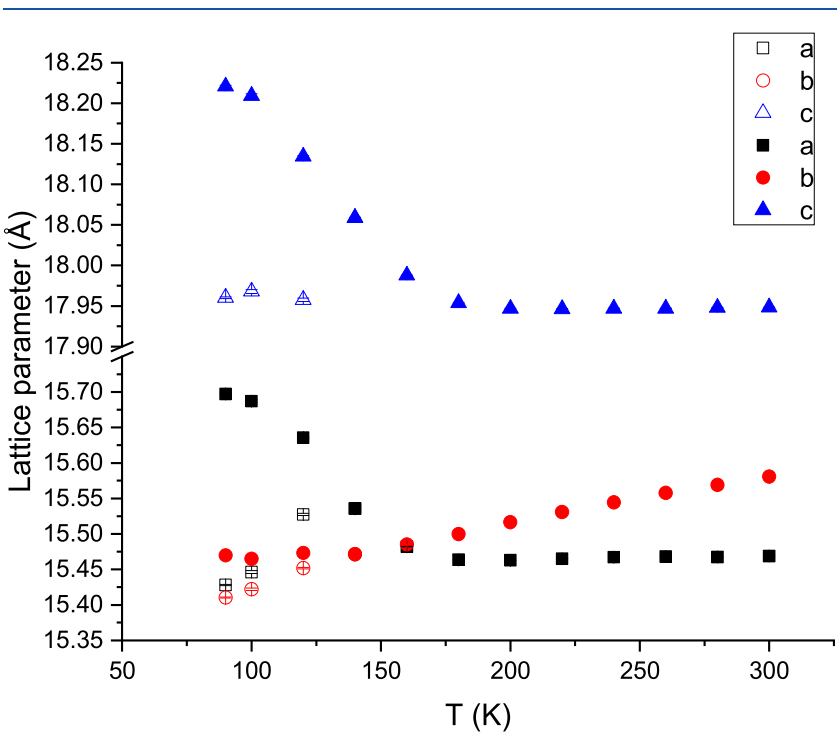

Figure 4. Variation in the unit cell parameters (lattice constants: $a, b$, c) for ZIF-62 at different temperatures and 1 bar pressure of $\mathrm{O}_{2}$. Empty symbols $=$ contracted phase; filled symbols $=$ expanded phase.

the variation in the unit cell parameters obtained from the Rietveld refinement analysis. The sample exposed to 1 bar pressure of $\mathrm{O}_{2}$ at $90 \mathrm{~K}$ shows the presence of two phases, an expanded phase (ZIF-62-ep- $\left.\mathrm{O}_{2}\right)$ with unit cell parameters $a=$ 15.697(1) $\AA, b=15.470(1) \AA, c=18.221(1) \AA$, and $v=$ 4424.6(5) $\AA^{3}$ (solid symbols in Figure 4), and a contracted phase (ZIF-62-cp-O $\mathrm{O}_{2}$ ) with cell parameters $a=15.4279(8) \AA$, $b=15.4104(7) \AA, c=17.9604(9) \AA$, and $v=4270.1(4) \AA^{3}$ (empty symbols in Figure 4). The ZIF-62-ep- $\mathrm{O}_{2}$ corresponds to ca. $3.8 \%$ volume expansion upon $\mathrm{O}_{2}$ dosing. These two phases prevail in the low-temperature region up to $140 \mathrm{~K}$, with the ZIF-62-cp- $\mathrm{O}_{2}$ disappearing at higher temperatures (Figures 4 and S13). The remaining phase exhibits a certain contraction down to $175 \mathrm{~K}$ (Figure S14), followed by a slight expansion up to $300 \mathrm{~K}$ with unit cell parameters $a=15.4688(4) \AA, b=$ 15.5810(4) $\AA, c=17.9484(6) \AA$, and $v=4325.9(2) \AA^{3}$. These values at $300 \mathrm{~K}$ and 1 bar pressure of $\mathrm{O}_{2}$ are rather similar to those described above for the activated ZIF-62 structure at 300 $\mathrm{K}$ under vacuum, thus reflecting the scarce uptake of $\mathrm{O}_{2}$ at room temperature in this system, in close agreement with the adsorption isotherms in Figures 2 and S9. The presence of these two regions in ZIF-62 upon dosing 1 bar of $\mathrm{O}_{2}$ (threshold temperature $150 \mathrm{~K}$-see Figure 4) and the disappearance of the ZIF-62-ep- $\mathrm{O}_{2}$ phase above this temperature (at ca. $160-170 \mathrm{~K}$ ) perfectly correlate with the theoretical predictions (region I and region II), and the large oxygen uptake below $170 \mathrm{~K}$.

We have performed similar experiments for ZIF-62 at $90 \mathrm{~K}$ dosing $\mathrm{N}_{2}$ up to 1 bar. Figure S15 shows the SXRPD patterns of ZIF-62 at $90 \mathrm{~K}$ loaded with $\mathrm{N}_{2}$ at different pressures. Interestingly, and contrary to the adsorption behavior described in Figure 2, $\mathrm{N}_{2}$ at $90 \mathrm{~K}$ is also able to produce significant structural changes in the XRD pattern upon adsorption. Similar to $\mathrm{O}_{2}$, the incorporation of $\mathrm{N}_{2}$ at $90 \mathrm{~K}$ and 1 bar gives rise to the development of two phases, the expanded phase (ZIF-62-ep- $\mathrm{N}_{2}$ ) with unit cell parameters $a=$ 
15.677(1) $\AA, b=15.459(1) \AA, c=18.206(1) \AA$, and $v=$ 4412.4(5) $\AA^{3}$, and the contracted phase (ZIF-62-cp- $\mathrm{N}_{2}$ ) with parameters $a=15.4035(5) \AA, b=15.4285(5) \AA, c=$ 17.9603(6) $\AA$, and $v=4268.3(3) \AA^{3}$ (see Figures 5 and S16)

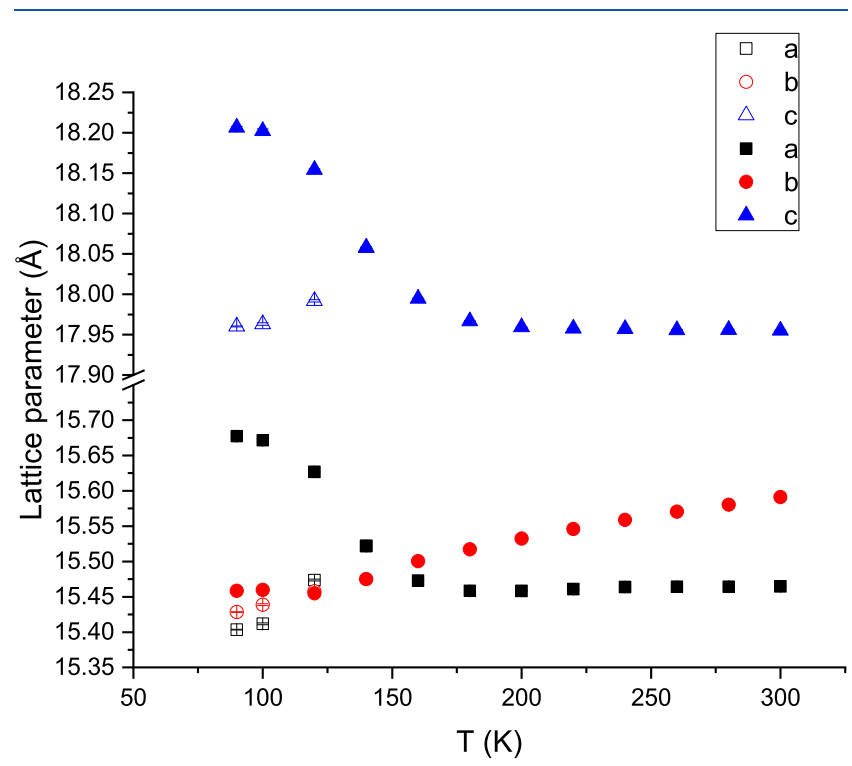

Figure 5. Variation in the unit cell parameters (lattice constants: $a, b$, c) for ZIF-62 at different temperatures and 1 bar pressure of $\mathrm{N}_{2}$. Empty symbols $=$ contracted phase; filled symbols $=$ expanded phase.

The expanded phase observed after $\mathrm{N}_{2}$ dosing corresponds to a $3.5 \%$ unit cell expansion. As described above for $\mathrm{O}_{2}$, the two phases prevail only at low temperatures, with the contracted phase disappearing at $140 \mathrm{~K}$. The smaller unit cell expansion upon $\mathrm{N}_{2}$ adsorption is also in correlation with the theoretical predictions for gas uptake (uptake at $90 \mathrm{~K}, \mathrm{O}_{2}>\mathrm{N}_{2}$ ).

These results clearly show that the performance of ZIF-62 under operando conditions is rather similar for $\mathrm{O}_{2}$ and $\mathrm{N}_{2}$ (although slightly favored for $\mathrm{O}_{2}$ ). Figure $\mathrm{S} 14$ compares the variation of the unit cell volume for both ZIF-62-cp and ZIF62-ep during the adsorption of both gases. The accesibility of $\mathrm{N}_{2}$ to the inner porosity in ZIF-62 at the synchrotron can be explained based on the different experimental conditions used at the synchrotron and at the gas adsorption equipment. These differences include a slightly different adsorption temperature (90 K vs $77 \mathrm{~K}$ ), a slightly smaller particle size (samples for SXRPD must be finely grounded) and the different dimensions of the reactor (experiments at the synchrotron are performed using a thin capillary reactor). These results confirm that the inaccessibility of nitrogen to the inner porous structure of ZIF62 at $77 \mathrm{~K}$ is not due to a pore size and shape restriction but rather to kinetic limitations due to the nature of the nitrogenframework interactions. Slightly larger temperatures are needed to overcome these kinetic restrictions, thus promoting an expanded phase able to accommodate both, $\mathrm{N}_{2}$ and $\mathrm{O}_{2}$.

3.5. Adsorption of Bulkier Molecules: Linear and Branched Hydrocarbons. As described above, although many ZIFs are characterized by small pore apertures (e.g., predicted limiting pore size window for ZIF-4 $\sim 0.21 \mathrm{~nm}$, ${ }^{4}$ ZIF-7 $\sim 0.3 \mathrm{~nm},{ }^{30}$ and ZIF-8 $\sim 0.34 \mathrm{~nm}^{45}$ ), previous studies have shown that these systems are able to adsorb larger molecules, such as hydrocarbons. ${ }^{13,46-48}$ A similar scenario could take place in ZIF-62 despite the small pore aperture $(0.14 \mathrm{~nm})$ predicted above by GCMC simulations. Despite the importance of hydrocarbon adsorption and separation, to our knowledge, there are no studies in the literature dealing with hydrocarbon adsorption in ZIF-62. The only studies are on its glassy counterpart, a ZIF-62, which is able to adsorb linear hydrocarbons (e.g., $n$-butane) with a significant uptake (up to $0.8 \mathrm{mmol} / \mathrm{g}$ ). However, this adsorption is irreversible due to the restricted accessibility of n-butane through the reduced pore size aperture of the glass $(0.25 \mathrm{~nm}) .^{28,49}$ These studies have anticipated that $a_{\mathrm{g}}$ ZIF-62 is also able to separate alkanes/ alkenes based on the faster diffusion of the unsaturated hydrocarbon. To evaluate the potential of crystalline ZIF-62 to separate hydrocarbons, we performed adsorption isotherms of linear hydrocarbons, methane, ethane, ethylene, propane, propylene, and n-hexane as well as branched ones, 2methylpentane and 2,2-dimethylbutane. In the case of linear hydrocarbons, we extended these studies to alkane/alkene to observe the effect of the unsaturated double bonds in the adsorption process. Figure 6 shows the adsorption isotherms of ZIF-62 at $298 \mathrm{~K}$ and up to atmospheric pressure. According to Figure $6 \mathrm{a}, \mathrm{b}$, all linear hydrocarbons are able to access the inner cavities in ZIF-62, independently of the kinetic diameter of the probe molecule (up to $0.43 \mathrm{~nm}$ for propane). This observation reinforces the hypothesis that the lack of accessibility for nitrogen at $77 \mathrm{~K}$ is not due to pore size inaccessibility but rather to kinetic restrictions due to the impossibility of $\mathrm{N}_{2}$ to promote the expanded phase at $77 \mathrm{~K}$. As expected, the adsorption uptake for hydrocarbon increases with the number of carbon atoms in the aliphatic chain from $\mathrm{C}_{1}(\sim 0.6 \mathrm{mmol} / \mathrm{g})$ up to $\mathrm{C}_{3}(\sim 1.4 \mathrm{mmol} / \mathrm{g})$ at $1 \mathrm{bar}$ and $298 \mathrm{~K}$. This behavior has also been observed for other porous materials, and it is attributed to the lower condensation pressure of $\mathrm{C}_{3}$ hydrocarbons vs their lower molecular mass counterparts, such as methane. ${ }^{12}$ Taking a closer look at the $C_{2}$ series, the experimental results show that ethane exhibits a higher uptake compared to ethylene over the whole pressure range evaluated. The preferential adsorption of the saturated hydrocarbon can be associated with its slightly larger kinetic diameter $(\sim 0.2 \AA)$ compared to its unsaturated counterpart, thus having a better fitting in the ZIF cavities and a higher adsorption energy. ${ }^{50}$ This phenomenon has also been observed in other ZIF materials, and it has been attributed to different reasons such as framework flexibility, ${ }^{12}$ cavity size, packing of the adsorbed molecules in the inner porosity of the ZIFs, and the presence of weak van der Waals interactions between the saturated hydrocarbon and the imidazole-based linker. ${ }^{51-53}$ In fact, previous studies for alkane/alkene adsorption have shown that the lack of open metal centers and charged surface groups in ZIFs promote the adsorption of the more polarizable paraffins through nonspecific interactions. ${ }^{52}$ Interestingly, the diffusion of the $\mathrm{C}_{2}$ hydrocarbons follows an opposite trend to the uptake, the smaller alkene (ethylene) exhibiting a shorter equilibration time (faster diffusion), in close agreement with previous results in $a_{\mathrm{g}}$ ZIF-62 (Figure S17 reflects the time needed for each point of the isotherm to reach equilibrium, i.e., equilibrium time at the manifold vs pressure) ${ }^{28}$ However, the adsorption uptake for hydrocarbons is much larger in the parent ZIF-62 compared to its glass counterpart. Only propane, with a larger chain length and a larger kinetic diameter, experience some limitations to access the porosity, with the adsorption isotherm exhibiting unexpected steps (e.g., at $p \sim 0.1-0.2$ bar) and marked irreversibility. The different performance of propane is also reflected in a reversed propane/ propylene selectivity (separation factor $<1$ ), compared to 

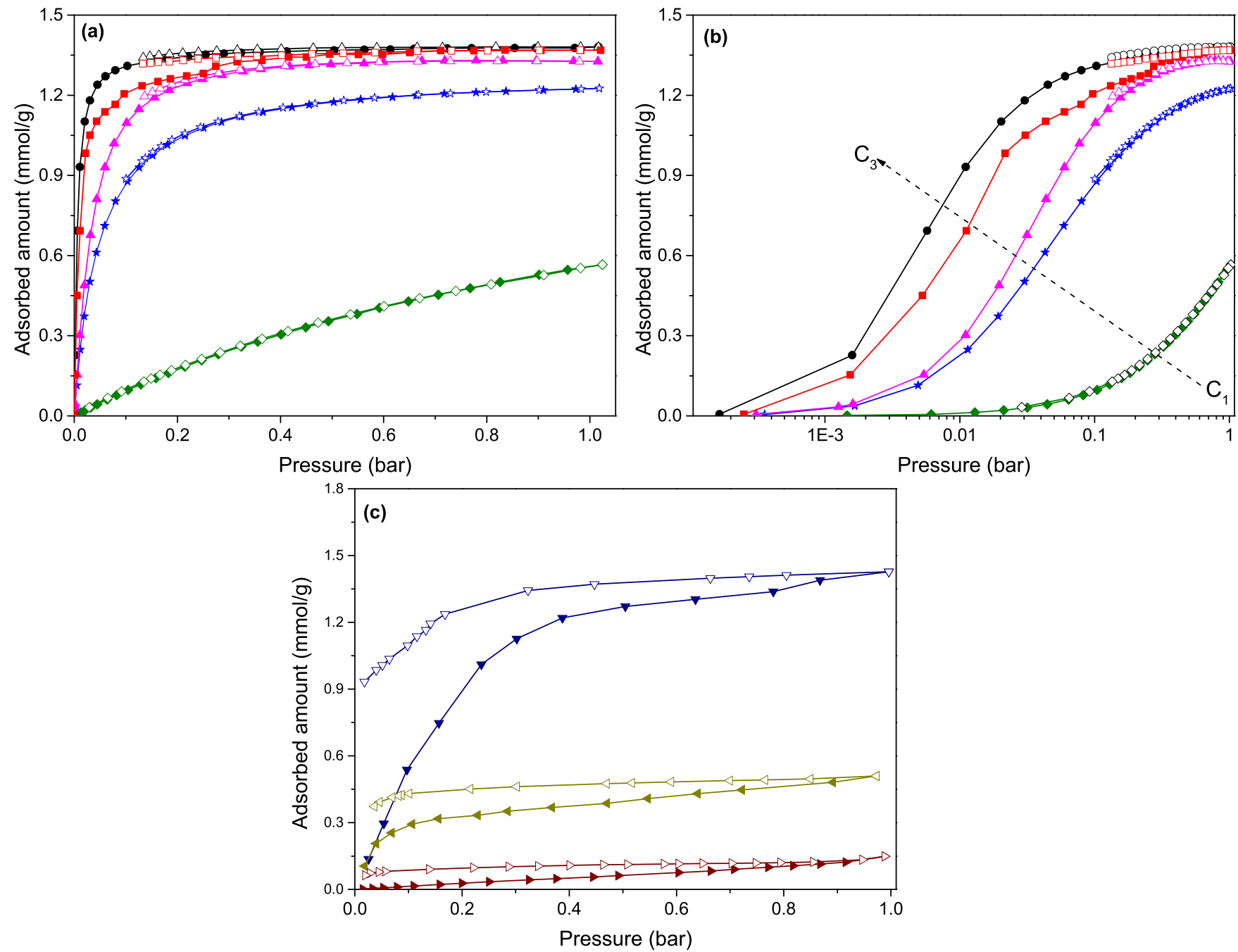

Figure 6. Adsorption (filled symbols) -desorption (empty symbols) isotherms for (a, b) linear and (c) branched hydrocarbons in ZIF-62 at $298 \mathrm{~K}$ and 1 bar (green diamond solid: methane, blue star solid: ethylene, pink triangle up solid: ethane, red box solid: propane, black circle solid: propylene, blue triangle down solid: $n$-hexane, olive triangle left-pointing solid: 2 -methylpentane, and brown triangle right-pointing solid: 2,2 dimethylbutane).

ethane/ethylene (separation factor $>1$ ). Ethane/ethylene adsorption capacity at $298 \mathrm{~K}$ for ZIF-62 (ca. 1.3/1.2 mmol/ g) resembles other ZIFs reported in the literature such as ZIF7 (ca. $1.8 / 1.8 \mathrm{mmol} / \mathrm{g}$ ), ${ }^{12} \mathrm{ZIF}-4$ (ca. $\left.2.2 / 2.1 \mathrm{mmol} / \mathrm{g}\right),{ }^{54}$ and ZIF-8 (ca. $2 / 1 \mathrm{mmol} / \mathrm{g}$ ). ${ }^{52}$ However, it is exceeded by other MOFs with Lewis sites (LS) or open metal sites (OMS) MOFs such as Mg-CPO-27 (ca. 5/6.5 mmol/g), ${ }^{52}$ HKUST-1 (7/7.8 $\mathrm{mmol} / \mathrm{g}$ ), ${ }^{55} \mathrm{MIL}-100$ (Fe) (ca. $\left.5 / 4 \mathrm{mmol} / \mathrm{g}\right),{ }^{56} \mathrm{Ni}($ btzip) $\left(\mathrm{H}_{2}\right.$ btzip) $2 \mathrm{DMF} \cdot 2 \mathrm{H}_{2} \mathrm{O}$ (ca. $\left.3.7 / 3.1 \mathrm{mmol} / \mathrm{g}\right){ }^{57}$ and Co(btzip) $\left(\mathrm{H}_{2}\right.$ btzip) $2 \mathrm{DMF} \cdot 2 \mathrm{H}_{2} \mathrm{O}$ (ca. $\left.3.5 / 5.4 \mathrm{mmol} / \mathrm{g}\right){ }^{58}$ However, these groups of decorated MOFs present challenges in terms of complex synthesis methods, ${ }^{59}$ use of dangerous chlorohydrin acid, ${ }^{57,58}$ and limited water stability. ${ }^{60-62}$

In the case of longer hydrocarbons (Figure 6c), n-hexane exhibits severe problems to access the inner cavities in ZIF-62, showing an irreversible hysteresis loop. The monobranched $\mathrm{C}_{6}$ isomer (2-methylpentane; kinetic diameter, $0.50 \mathrm{~nm}$ ) exhibits a sudden decrease in the amount uptake (down to $\sim 0.5 \mathrm{mmol}$ / $\mathrm{g})$, whereas the dibranched isomer (2,2-dimethylbutane; kinetic diameter, $0.62 \mathrm{~nm}$ ) is mainly excluded from the porosity. These results confirm that the pore size aperture and pore accessibility of ZIF-62 are larger than the crystallographic pore opening predicted by Monte Carlo $(0.14 \mathrm{~nm})$ and close to the kinetic diameter of $\mathrm{C}_{3}-\mathrm{C}_{6}$ saturated hydrocarbons, i.e., ca. $0.43 \mathrm{~nm}$. The unexpected accessibility for bulkier hydrocarbons and the variation of the pressure threshold for each individual molecule $\left(\mathrm{C}_{1}-\mathrm{C}_{2}-\mathrm{C}_{3}\right.$ selectivity and alkane/ alkene selectivity) can only be understood due to the presence of specific interactions between the hydrocarbon molecules and the ZIF-62 framework at $298 \mathrm{~K}$ with the associated structural changes and, in particular, to a potential breathing effect from a narrow pore to an expanded phase, as anticipated by synchrotron X-ray powder diffraction measurements for $\mathrm{N}_{2}$ and $\mathrm{O}_{2}$.

\section{CONCLUSIONS}

Structural changes taking place in nanoporous ZIF-62 upon gas adsorption and the associated benefits for the selective adsorption of different probe molecules have been carefully evaluated through the combination of single-component gas adsorption measurements, including synchrotron X-ray powder diffraction and Monte Carlo simulations. Experimental results show that the nanoporous mixed-linker ZIF-62 is able to adsorb a considerable amount of $\mathrm{O}_{2}$ (up to $8 \mathrm{mmol} / \mathrm{g}$ at $77 \mathrm{~K}$ ), 
whereas $\mathrm{N}_{2}$, under the same experimental conditions, is not able to access the inner porous structure. In situ synchrotron X-ray powder diffraction measurements confirm that ZIF-62 experiences a breathing effect upon gas adsorption from a narrow pore structure (np) to an expanded (ep) network (ca. $3.8 \%$ volume expansion) at $90 \mathrm{~K}$. The similarity in the structural changes for $\mathrm{O}_{2}$ and $\mathrm{N}_{2}$ suggests that the gasframework interactions at $77 \mathrm{~K}$ define the adsorption performance for these two probe molecules, with these kinetic restrictions for $\mathrm{N}_{2}$ vanishing at $90 \mathrm{~K}$. Although theoretical predictions anticipate a pore size window of $0.14 \mathrm{~nm}$ in ZIF62 , single-component gas adsorption measurements show that linear and even monobranched hydrocarbons are indeed able to access the porosity, in close agreement with the structural changes (structural expansion) predicted by SXRPD measurements.

\section{ASSOCIATED CONTENT}

\section{SI Supporting Information}

The Supporting Information is available free of charge at https://pubs.acs.org/doi/10.1021/acsanm.1c00010.

Computational details, synchrotron X-ray diffraction patterns and Rietveld refinement calculations, thermogravimetric analysis, and adsorption isotherms: experimental and simulated (PDF)

Input files for RASPA, models for adsorbates, force field definition, and crystallographic data for ZIF-62 (ZIP)

\section{AUTHOR INFORMATION}

\section{Corresponding Author}

Joaquin Silvestre-Albero - Laboratorio de Materiales Avanzados, Departamento de Química Inorgánica-Instituto Universitario de Materiales, Universidad de Alicante, 03690 San Vicente del Raspeig, Alicante, Spain; 이잉.org/00000002-0303-0817; Email: joaquin.silvestre@ua.es

\section{Authors}

Jesus Gandara-Loe - Laboratorio de Materiales Avanzados, Departamento de Química Inorgánica-Instituto Universitario de Materiales, Universidad de Alicante, 03690 San Vicente del Raspeig, Alicante, Spain; 이이이.org/0000-0003-13344788

Rocio Bueno-Perez - Adsorption \& Advanced Materials Laboratory $\left(A^{2} M L\right)$, Department of Chemical Engineering \& Biotechnology, University of Cambridge, Cambridge CB3 OAS, United Kingdom

Alexander Missyul - CELLS-ALBA Synchrotron, 08290

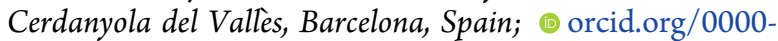
0002-0577-4481

David Fairen-Jimenez - Adsorption \& Advanced Materials Laboratory $\left(A^{2} M L\right)$, Department of Chemical Engineering \& Biotechnology, University of Cambridge, Cambridge CB3 OAS, United Kingdom; (1) orcid.org/0000-0002-5013-1194

Complete contact information is available at:

https://pubs.acs.org/10.1021/acsanm.1c00010

\section{Author Contributions}

J.G.-L. performed the synthesis of the ZIF-62 material and the physicochemical characterization; A.M. was responsible for the synchrotron XRD measurements and their interpretation; R.B.P. performed the theoretical calculations; and D.F.-J. and J.S.A. coordinated all of the research activities and participated in the discussion of the results. All authors participated in the preparation of the manuscript.

Notes

The authors declare no competing financial interest.

\section{ACKNOWLEDGMENTS}

J.S.-A. acknowledges financial support from the MINECO (Projects MAT2016-80285-p and PID2019-108453GB-C21). The authors acknowledge ALBA for providing beamtime (Project No. 2019023264). Computational work was supported by the Cambridge High-Performance Computing Service, the Cambridge Service for Data-Driven Discovery (CSD3).

\section{REFERENCES}

(1) Yang, R. T. Gas Separation by Adsorption Processes; Elsevier, 1987.

(2) Baker, R. W. Future Directions of Membrane Gas Separation Technology. Ind. Eng. Chem. Res. 2002, 41, 1393-1411.

(3) Chong, K. C.; Lai, S. O.; Thiam, H. S.; Teoh, H. C.; Heng, S. L. Recent Progress of Oxygen/Nitrogen Separation Using Membrane Technology. J. Eng. Sci. Technol. 2016, 11, 1016-1030.

(4) Andriani, D.; Wresta, A.; Atmaja, T. D.; Saepudin, A. A Review on Optimization Production and Upgrading Biogas Through $\mathrm{CO}_{2}$ Removal Using Various Techniques. Appl. Biochem. Biotechnol. 2014, $172,1909-1928$.

(5) Chen, X. Y.; Vinh-Thang, H.; Ramirez, A. A.; Rodrigue, D.; Kaliaguine, S. Membrane Gas Separation Technologies for Biogas Upgrading. RSC Adv. 2015, 5, 24399-24448.

(6) Palomino, M.; Corma, A.; Rey, F.; Valencia, S. New Insights on $\mathrm{CO}_{2}$-Methane Separation Using LTA Zeolites with Different Si/Al Ratios and a First Comparison with MOFs. Langmuir 2010, 26, 1910-1917.

(7) Bae, Y.-S.; Snurr, R. Q. Development and Evaluation of Porous Materials for Carbon Dioxide Separation and Capture. Angew. Chem. Int. Ed. 2011, 50, 11586-11596.

(8) Park, K. S.; Ni, Z.; Cote, A. P.; Choi, J. Y.; Huang, R.; UribeRomo, F. J.; Chae, H. K.; O’Keeffe, M.; Yaghi, O. M. Exceptional Chemical and Thermal Stability of Zeolitic Imidazolate Frameworks. Proc. Natl. Acad. Sci. U.S.A. 2006, 103, 10186-10191.

(9) Fairen-Jimenez, D.; Moggach, S. A.; Wharmby, M. T.; Wright, P. A.; Parsons, S.; Düren, T. Opening the Gate: Framework Flexibility in ZIF-8 Explored by Experiments and Simulations. J. Am. Chem. Soc. 2011, 133, 8900-8902.

(10) Zhang, L.; Wu, G.; Jiang, J. Adsorption and Diffusion of $\mathrm{CO}_{2}$ and $\mathrm{CH}_{4}$ in Zeolitic Imidazolate Framework-8: Effect of Structural Flexibility. J. Phys. Chem. C 2014, 118, 8788-8794.

(11) Casco, M. E.; Cheng, Y. Q.; Daemen, L. L.; Fairen-Jimenez, D.; Ramos-Fernández, E. V.; Ramirez-Cuesta, A. J.; Silvestre-Albero, J. Gate-Opening Effect in ZIF-8: The First Experimental Proof Using Inelastic Neutron Scattering. Chem. Commun. 2016, 52, 3639-3642.

(12) Gücüyener, C.; van den Bergh, J.; Gascon, J.; Kapteijn, F. Ethane/Ethene Separation Turned on Its Head: Selective Ethane Adsorption on the Metal-Organic Framework ZIF-7 through a GateOpening Mechanism. J. Am. Chem. Soc. 2010, 132, 17704-17706.

(13) Fairen-Jimenez, D.; Galvelis, R.; Torrisi, A.; Gellan, A. D.; Wharmby, M. T.; Wright, P. A.; Mellot-Draznieks, C.; Düren, T. Flexibility and Swing Effect on the Adsorption of Energy-Related Gases on ZIF-8: Combined Experimental and Simulation Study. Dalton Trans. 2012, 41, 10752.

(14) Gandara-Loe, J.; Missyul, A.; Fauth, F.; Daemen, L. L.; Cheng, Y. Q.; Ramirez-Cuesta, A. J.; Ravikovitch, P. I.; Silvestre-Albero, J. New Insights into the Breathing Phenomenon in ZIF-4. J. Mater. Chem. A 2019, 7, 14552-14558.

(15) Bennett, T. D.; Simoncic, P.; Moggach, S. A.; Gozzo, F.; Macchi, P.; Keen, D. A.; Tan, J.-C.; Cheetham, A. K. Reversible 
Pressure-Induced Amorphization of a Zeolitic Imidazolate Framework (ZIF-4). Chem. Commun. 2011, 47, 7983.

(16) Zhao, P.; Lampronti, G. I.; Lloyd, G. O.; Wharmby, M. T.; Facq, S.; Cheetham, A. K.; Redfern, S. A. T. Phase Transitions in Zeolitic Imidazolate Framework 7: The Importance of Framework Flexibility and Guest-Induced Instability. Chem. Mater. 2014, 26, 1767-1769.

(17) Zhao, P.; Fang, H.; Mukhopadhyay, S.; Li, A.; Rudić, S.; McPherson, I. J.; Tang, C. C.; Fairen-Jimenez, D.; Tsang, S. C. E.; Redfern, S. A. T. Structural Dynamics of a Metal-Organic Framework Induced by $\mathrm{CO}_{2}$ Migration in Its Non-Uniform Porous Structure. Nat. Commun. 2019, 10, No. 999.

(18) Wharmby, M. T.; Henke, S.; Bennett, T. D.; Bajpe, S. R.; Schwedler, I.; Thompson, S. P.; Gozzo, F.; Simoncic, P.; MellotDraznieks, C.; Tao, H.; Yue, Y.; Cheetham, A. K. Extreme Flexibility in a Zeolitic Imidazolate Framework: Porous to Dense Phase Transition in Desolvated ZIF-4. Angew. Chem., Int. Ed. 2015, 54, 6447-6451.

(19) Moggach, S. A.; Bennett, T. D.; Cheetham, A. K. The Effect of Pressure on ZIF-8: Increasing Pore Size with Pressure and the Formation of a High-Pressure Phase at $1.47 \mathrm{GPa}$. Angew. Chem., Int. Ed. 2009, 48, 7087-7089.

(20) Ania, C. O.; García-Pérez, E.; Haro, M.; Gutiérrez-Sevillano, J. J.; Valdés-Solís, T.; Parra, J. B.; Calero, S. Understanding Gas-Induced Structural Deformation of ZIF-8. J. Phys. Chem. Lett. 2012, 3, 11591164.

(21) Kwon, H. T.; Jeong, H.-K. In Situ Synthesis of Thin ZeoliticImidazolate Framework ZIF-8 Membranes Exhibiting Exceptionally High Propylene/Propane Separation. J. Am. Chem. Soc. 2013, 135, 10763-10768.

(22) Song, Q.; Nataraj, S. K.; Roussenova, M. V.; Tan, J. C.; Hughes, D. J.; Li, W.; Bourgoin, P.; Alam, M. A.; Cheetham, A. K.; AlMuhtaseb, S. A.; Sivaniah, E. Zeolitic Imidazolate Framework (ZIF-8) Based Polymer Nanocomposite Membranes for Gas Separation. Energy Environ. Sci. 2012, 5, 8359-8369.

(23) Li, Y.; Liang, F.; Bux, H.; Yang, W.; Caro, J. Zeolitic Imidazolate Framework ZIF-7 Based Molecular Sieve Membrane for Hydrogen Separation. J. Membr. Sci. 2010, 354, 48-54.

(24) Cuadrado-Collados, C.; Fernández-Català, J.; Fauth, F.; Cheng, Y. Q.; Daemen, L. L.; Ramirez-Cuesta, A. J.; Silvestre-Albero, J. Understanding the Breathing Phenomena in Nano-ZIF-7 upon Gas Adsorption. J. Mater. Chem. A 2017, 5, 20938-20946.

(25) Hobday, C. L.; Bennett, T. D.; Fairen-Jimenez, D.; Graham, A. J.; Morrison, C. A.; Allan, D. R.; Düren, T.; Moggach, S. A. Tuning the Swing Effect by Chemical Functionalization of Zeolitic Imidazolate Frameworks. J. Am. Chem. Soc. 2018, 140, 382-387.

(26) Gustafsson, M.; Zou, X. Crystal Formation and Size Control of Zeolitic Imidazolate Frameworks with Mixed Imidazolate Linkers. J. Porous Mater. 2013, 20, 55-63.

(27) Bennett, T. D.; Yue, Y.; Li, P.; Qiao, A.; Tao, H.; Greaves, N. G.; Richards, T.; Lampronti, G. I.; Redfern, S. A. T.; Blanc, F.; Farha, O. K.; Hupp, J. T.; Cheetham, A. K.; Keen, D. A. Melt-Quenched Glasses of Metal-Organic Frameworks. J. Am. Chem. Soc. 2016, 138, 3484-3492.

(28) Frentzel-Beyme, L.; Kloß, M.; Kolodzeiski, P.; Pallach, R.; Henke, S. Meltable Mixed-Linker Zeolitic Imidazolate Frameworks and Their Microporous Glasses: From Melting Point Engineering to Selective Hydrocarbon Sorption. J. Am. Chem. Soc. 2019, 141, $12362-12371$.

(29) Wang, Y.; Jin, H.; Ma, Q.; Mo, K.; Mao, H.; Feldhoff, A.; Cao, X.; Li, Y.; Pan, F.; Jiang, Z. A MOF Glass Membrane for Gas Separation. Angew. Chem., Int. Ed. 2020, 59, 4365-4369.

(30) Banerjee, R.; Phan, A.; Wang, B.; Knobler, C.; Furukawa, H.; O'Keeffe, M.; Yaghi, O. M. High-Throughput Synthesis of Zeolitic Imidazolate Frameworks and Application to $\mathrm{CO}_{2}$ Capture. Science 2008, 319, 939-943.

(31) Dubbeldam, D.; Calero, S.; Ellis, D. E.; Snurr, R. Q. RASPA: Molecular Simulation Software for Adsorption and Diffusion in Flexible Nanoporous Materials. Mol. Simul. 2016, 42, 81-101.
(32) Sarkisov, L.; Harrison, A. Computational Structure Characterisation Tools in Application to Ordered and Disordered Porous Materials. Mol. Simul. 2011, 37, 1248-1257.

(33) Zhang, L.; Siepmann, J. I. Direct Calculation of Henry's Law Constants from Gibbs Ensemble Monte Carlo Simulations: Nitrogen, Oxygen, Carbon Dioxide and Methane in Ethanol. Theor. Chem. Acc. 2006, 115, 391-397.

(34) Potoff, J. J.; Siepmann, J. I. Vapor-Liquid Equilibria of Mixtures Containing Alkanes, Carbon Dioxide, and Nitrogen. AIChE J. 2001, 47, 1676-1682.

(35) Sevillano, J. J. G.; Calero, S.; Ania, C. O.; Parra, J. B.; Kapteijn, F.; Gascon, J.; Hamad, S. Toward a Transferable Set of Charges to Model Zeolitic Imidazolate Frameworks: Combined ExperimentalTheoretical Research. J. Phys. Chem. C 2013, 117, 466-471.

(36) Wu, X.; Huang, J.; Cai, W.; Jaroniec, M. Force Field for ZIF-8 Flexible Frameworks: Atomistic Simulation of Adsorption, Diffusion of Pure Gases as $\mathrm{CH}_{4}, \mathrm{H}_{2}, \mathrm{CO}_{2}$ and $\mathrm{N}_{2}$. RSC Adv. 2014, 4, 1650316511.

(37) Liu, Q.; Wang, T.; Qiu, J.; Cao, Y. A Novel Carbon/ZSM-5 Nanocomposite Membrane with High Performance for Oxygen/ Nitrogen Separation. Chem. Commun. 2006, 193, 1230.

(38) Park, Y.-J.; Lee, S.-J.; Moon, J.-H.; Choi, D.-K.; Lee, C.-H. Adsorption Equilibria of $\mathrm{O}_{2}, \mathrm{~N}_{2}$, and Ar on Carbon Molecular Sieve and Zeolites 10X, 13X, and LiX. J. Chem. Eng. Data 2006, 51, 10011008.

(39) Moghadam, P. Z.; Islamoglu, T.; Goswami, S.; Exley, J.; Fantham, M.; Kaminski, C. F.; Snurr, R. Q.; Farha, O. K.; FairenJimenez, D. Computer-Aided Discovery of a Metal-Organic Framework with Superior Oxygen Uptake. Nat. Commun. 2018, 9, No. 1378.

(40) Dincă, M.; Yu, A. F.; Long, J. R. Microporous Metal-Organic Frameworks Incorporating 1,4-Benzeneditetrazolate: Syntheses, Structures, and Hydrogen Storage Properties. J. Am. Chem. Soc. 2006, 128, 8904-8913.

(41) Humphrey, S. M.; Chang, J.-S.; Jhung, S. H.; Yoon, J. W.; Wood, P. T. Porous Cobalt(II)-Organic Frameworks with Corrugated Walls: Structurally Robust Gas-Sorption Materials. Angew. Chem., Int. Ed. 2007, 46, 272-275.

(42) Dincă, M.; Dailly, A.; Liu, Y.; Brown, C. M.; Neumann, D. A.; Long, J. R. Hydrogen Storage in a Microporous Metal-Organic Framework with Exposed $\mathrm{Mn}^{2+}$ Coordination Sites. J. Am. Chem. Soc. 2006, 128, 16876-16883.

(43) Tian, T.; Wharmby, M. T.; Parra, J. B.; Ania, C. O.; FairenJimenez, D. Role of Crystal Size on Swing-Effect and Adsorption Induced Structure Transition of ZIF-8. Dalton Trans. 2016, 45, 6893-6900.

(44) Bennett, T. D.; Cao, S.; Tan, J. C.; Keen, D. A.; Bithell, E. G.; Beldon, P. J.; Friscic, T.; Cheetham, A. K. Facile Mechanosynthesis of Amorphous Zeolitic Imidazolate Frameworks. J. Am. Chem. Soc. 2011, 133, 14546-14549.

(45) Hobday, C. L.; Woodall, C. H.; Lennox, M. J.; Frost, M.; Kamenev, K.; Düren, T.; Morrison, C. A.; Moggach, S. A. Understanding the Adsorption Process in ZIF-8 Using High Pressure Crystallography and Computational Modelling. Nat. Commun. 2018, 9, No. 1429.

(46) Peralta, D.; Chaplais, G.; Paillaud, J.-L.; Simon-Masseron, A.; Barthelet, K.; Pirngruber, G. D. The Separation of Xylene Isomers by ZIF-8: A Demonstration of the Extraordinary Flexibility of the ZIF-8 Framework. Microporous Mesoporous Mater. 2013, 173, 1-5.

(47) Knebel, A.; Geppert, B.; Volgmann, K.; Kolokolov, D. I.; Stepanov, A. G.; Twiefel, J.; Heitjans, P.; Volkmer, D.; Caro, J. Defibrillation of Soft Porous Metal-Organic Frameworks with Electric Fields. Science 2017, 358, 347-351.

(48) Polyukhov, D. M.; Poryvaev, A. S.; Gromilov, S. A.; Fedin, M. V. Precise Measurement and Controlled Tuning of Effective Window Sizes in ZIF-8 Framework for Efficient Separation of Xylenes. Nano Lett. 2019, 19, 6506-6510.

(49) Longley, L.; Collins, S. M.; Li, S.; Smales, G. J.; Erucar, I.; Qiao, A.; Hou, J.; Doherty, C. M.; Thornton, A. W.; Hill, A. J.; Yu, X.; Terrill, N. J.; Smith, A. J.; Cohen, S. M.; Midgley, P. A.; Keen, D. A.; 
Telfer, S. G.; Bennett, T. D. Flux Melting of Metal-Organic Frameworks. Chem. Sci. 2019, 10, 3592-3601.

(50) Krokidas, P.; Castier, M.; Moncho, S.; Brothers, E.; Economou, I. G. Molecular Simulation Studies of the Diffusion of Methane, Ethane, Propane, and Propylene in ZIF-8. J. Phys. Chem. C 2015, 119, 27028-27037.

(51) Wu, Y.; Chen, H.; Liu, D.; Qian, Y.; Xi, H. Adsorption and Separation of Ethane/Ethylene on ZIFs with Various Topologies: Combining GCMC Simulation with the Ideal Adsorbed Solution Theory (IAST). Chem. Eng. Sci. 2015, 124, 144-153.

(52) Böhme, U.; Barth, B.; Paula, C.; Kuhnt, A.; Schwieger, W.; Mundstock, A.; Caro, J.; Hartmann, M. Ethene/Ethane and Propene/ Propane Separation via the Olefin and Paraffin Selective MetalOrganic Framework Adsorbents CPO-27 and ZIF-8. Langmuir 2013, 29, 8592-8600.

(53) Pan, Y.; Li, T.; Lestari, G.; Lai, Z. Effective Separation of Propylene/Propane Binary Mixtures by ZIF-8 Membranes. J. Membr. Sci. 2012, 390-391, 93-98.

(54) Hartmann, M.; Böhme, U.; Hovestadt, M.; Paula, C. Adsorptive Separation of Olefin/Paraffin Mixtures with ZIF-4. Langmuir 2015, 31, 12382-12389.

(55) Martins, V. F. D.; Ribeiro, A. M.; Ferreira, A.; Lee, U.-H.; Hwang, Y. K.; Chang, J.-S.; Loureiro, J. M.; Rodrigues, A. E. Ethane/ Ethylene Separation on a Copper Benzene-1,3,5-Tricarboxylate MOF. Sep. Purif. Technol. 2015, 149, 445-456.

(56) Martins, V. F. D.; Seabra, R.; Silva, P.; Ribeiro, A. M.; Cho, K. H.; Lee, U.-H.; Chang, J.-S.; Loureiro, J. M.; Rodrigues, A. E.; Ferreira, A. $\mathrm{C}_{2} / \mathrm{C}_{3}$ Hydrocarbon Separation by Pressure Swing Adsorption on MIL-100(Fe). Ind. Eng. Chem. Res. 2020, 59, 1056810582.

(57) Li, Y.-Z.; Wang, H.-H.; Yang, H.-Y.; Hou, L.; Wang, Y.-Y.; Zhu, Z. An Uncommon Carboxyl-Decorated Metal-Organic Framework with Selective Gas Adsorption and Catalytic Conversion of $\mathrm{CO}_{2}$. Chem. - Eur. J. 2018, 24, 865-871.

(58) Li, Y.-Z.; Wang, G.-D.; Shi, W.-J.; Hou, L.; Wang, Y.-Y.; Zhu, Z. Efficient $\mathrm{C}_{2} \mathrm{H}_{\mathrm{n}}$ Hydrocarbons and VOC Adsorption and Separation in an MOF with Lewis Basic and Acidic Decorated Active Sites. ACS Appl. Mater. Interfaces 2020, 12, 41785-41793.

(59) Ding, M.; Flaig, R. W.; Jiang, H.-L.; Yaghi, O. M. Carbon Capture and Conversion Using Metal-Organic Frameworks and MOF-Based Materials. Chem. Soc. Rev. 2019, 48, 2783-2828.

(60) Álvarez, J. R.; Sánchez-González, E.; Pérez, E.; SchneiderRevueltas, E.; Martínez, A.; Tejeda-Cruz, A.; Islas-Jácome, A.; González-Zamora, E.; Ibarra, I. A. Structure Stability of HKUST-1 towards Water and Ethanol and Their Effect on Its $\mathrm{CO}_{2}$ Capture Properties. Dalton Trans. 2017, 46, 9192-9200.

(61) Liu, B.; Vikrant, K.; Kim, K.-H.; Kumar, V.; Kailasa, S. K. Critical Role of Water Stability in Metal-Organic Frameworks and Advanced Modification Strategies for the Extension of Their Applicability. Environ. Sci. Nano 2020, 7, 1319-1347.

(62) Burtch, N. C.; Jasuja, H.; Walton, K. S. Water Stability and Adsorption in Metal-Organic Frameworks. Chem. Rev. 2014, 114, 10575-10612.

\section{NOTE ADDED AFTER ASAP PUBLICATION}

This paper was published ASAP on March 19, 2021 with an incorrect image for Scheme 1. The error was corrected and the revised manuscript was reposted on March 26, 2021. 